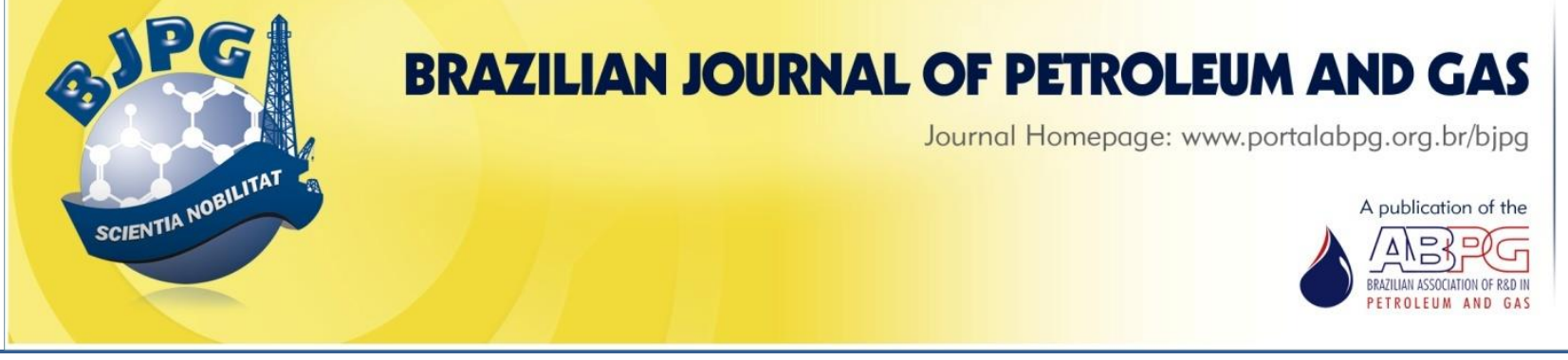

\title{
PRESSURE DROP IN CEMENT SLURRIES FLOW IN CIRCULAR AND ANNULAR REGIONS IN PRIMARY COMPLETION
}

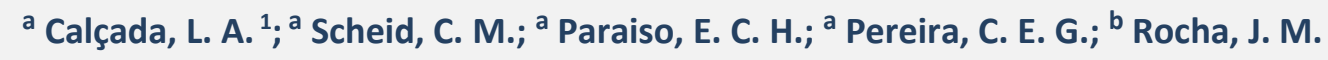 \\ ${ }^{a}$ Department of Chemical Engineering, Institute of technology, Federal Rural University of Rio de Janeiro, RJ, Brazil \\ ${ }^{b}$ Cenpes/Petrobrás, Research Center Leopoldo Miguez de Mello, Rio de Janeiro, Brazil
}

\begin{abstract}
This research focuses on predicting pressure drop in cement slurries flow in circular and annular regions. Friction factor correlations, hydraulic diameter, and rheological models were evaluated. Experimental data was taken in a cement slurry flow loop consisting of one positive displacement pump of 25-HP connected to a 230-liter tank agitated by a 3-HP mixer. Temperature was kept constant using a chiller system. A FANN viscometer 35A was used to obtain rheological data for each experiment. The cement slurry was composed of a mixture consisting of cement, fresh water, and additives (mid-temp retarder and antifoam agent). This slurry was produced in a mixing tank. Rheological models as power-law, Bingham, and Herschel-Buckley were evaluated to model fluid behavior. Results showed that the choice of rheological model affects hydraulic diameter, friction factor correlations, and regime transition determination. Some combinations of these correlations could accurately predict pressure drop data.
\end{abstract}

\section{KEYWORDS}

primary completion; pressure drop; cementing oil wells

\footnotetext{
${ }^{1}$ To whom all correspondence should be addressed.

Address: Department of Chemical Engineering, Institute of Technology, Federal Rural University of Rio de Janeiro, BR 465, Km 7, UFRRJ Campus, Seropédica-RJ, Brazil.

CEP: 23890-000 | Telephone/Fax number: (55) 21 3787-8742/ (55) 21 3787-3750 |e-mail: calcada@ufrrj.br doi:10.5419/bjpg2013-0011
} 


\section{INTRODUCTION}

During primary completion in oil and gas wells, the cement slurry flows in circular and annular regions. This flow occurs, respectively, inside the casing and between the casing and the rock formation. Cement slurry is pumped from the circular drilling tube to the annular region formed between the outside casing and the rock formation. The slurry ends its curing process forming a hydraulic seal in the well. The hydraulic seal provides a zonal isolation that fixes and protects the casing column and provides mechanical support to the geological formation drilled (Nelson, 1990; Bourgoyne et al., 1991).

Some concerns that arise during the while cementing of an oil well are the friction pressure and the pumping fluid speed along the well column. High pressure and high speed are used as an efficient maneuver to remove drilling fluid and cuttings. However, according to Nelson (1990), the pressure drop must be controlled to prevent the slurry from entering into the formation, and, also, to avoid the influx of formation fluids into the well, causing kicks. In an uncontrolled way major accidents may result as blowouts (Lake \& Mitchel, 2006). To prevent these problems, the hydrostatic pressure in the formation must be, in most cases, less than the fracture pressure and higher than the pore pressure.

This research focused on evaluating mathematical models that can be used to predict pressure drop in well design or during pumping procedures. For this purpose, experimental data were collected in a fluid flow loop that simulates the cement slurry flow. The experimental unit was designed based on the real process, during the primary cementing of oil wells. This experimental setup is able to provide pressure drop and fluid flow data in circular and annular regions under controlled temperature. The data were used to evaluate correlations for pressure drop's prediction during the cementing process. The friction factor and hydraulic diameter correlations were evaluated along with flow regime transitions. Cement samples were taken from the experimental unit tank during pressure drop tests. Then, the samples were placed in a viscometer FANN (model $35 \mathrm{~A})$ to measure their rheology.

\section{LITERATURE REVIEW}

\subsection{Rheological models}

For shear stress evaluation the experiment used a Newtonian fluid, Equation 1, and for nonNewtonian cement slurry it used power-law, Equation 2, and Bingham, Equation 3, (Fox et al., 2004).

$$
\begin{aligned}
& \tau=\mu \gamma \\
& \tau=k \gamma^{n} \\
& \tau=V P_{B} \gamma+L E_{B}
\end{aligned}
$$

Where $\tau$ is the shear stress, $\mu$ is the dynamic viscosity, $v$ is the shear rate, $k$ and $n$ are the consistency index and the behavior index of power law model, respectively, $V P_{B}$ is the Bingham plastic viscosity, and $L E_{B}$ is the yield stress for Bingham fluid. In addition to these, a model that accounts for characteristics of power law and Bingham models was used, as mentioned above. This model is known as the Herschel-Buckley, Equation 4.

$$
\tau=k_{H B} \gamma^{n_{H B}}+L E_{H B}
$$

Where the parameters $k_{H B}$ and $n_{H B}$ are, respectively, the consistency index and the behavior index of Herschel-Buckley model, and $L E_{H B}$ is the yield stress for Herschel-Buckley fluid. Bingham and power-law parameters were obtained from a linearization of their equations. The Herschel-Buckley parameters were determined by applying the least square method.

\subsection{Friction factor determination}

Replacing pressure drop equation distributed in a modified Bernoulli equation, one can determine the experimental friction factor (Equation 5). It uses the pressure data between two points on a straight stretch of the same area without the presence of accidents and the supply or removal of energy from that stretch (Bird et al., 2002).

$$
f=\frac{\Delta P D}{2 \rho L\langle v\rangle^{2}}
$$


In the Equation5, the Fanning friction factor is represented by $f ; \Delta P$ is the pressure loss; $D$ is the diameter of the circular pipe, or the hydraulic diameter; $\rho$ is the fluid density; $L$ is the length of the straight section; and $\langle\nu\rangle$ is the average velocity. For non-Newtonian fluids, the friction factor equations, in laminar flow, are developed for each rheological model. The power-law model, Equation 6, depends only on the Reynolds number. In this case, the particular Reynolds number is represented by $\mathrm{Re}_{\mathrm{p}}$.

$$
f=\frac{16}{R e_{P}}
$$

Where:

$$
\operatorname{Re}_{P}=\frac{D\langle v\rangle \rho}{k\left(\frac{8 v}{D}\right)^{n-1}\left(\frac{3 n+1}{4 n}\right)^{n}}
$$

The generalized Reynolds number for power law model is represented by $R e_{p}$ and $v$ is the average velocity. For the Bingham model, Equation8 is applied in laminar flow. This equation is a function of the Reynolds number ( $R e$ ) and the Hedstrom number $(\mathrm{He})$, which are dimensionless models.

$$
f=\frac{16}{R e_{B}}\left[1+\frac{H e_{B}}{6 R e_{B}}-\frac{H e_{B}^{4}}{3 f^{3} R e_{B}^{7}}\right]
$$

Where:

$$
\begin{aligned}
R e_{B} & =\frac{D\langle v\rangle \rho}{V P_{B}} \\
H e_{B} & =\frac{D^{2} \rho L E_{B}}{V P_{B}^{2}}
\end{aligned}
$$

Where $R e_{B}$ and $H e_{B}$, are the generalized Reynolds number and the Hedstrom number, both for the Bingham model. The Herschel-Buckley model is more complex than the models mentioned above. Such complexity is created by to the laminar friction factor that, in this case, depends on not only the dimensionless $\mathrm{He}_{\mathrm{HB}}$ and $\mathrm{Re}_{\mathrm{HB}}$ but on the wall stress parameter $\tau_{w}$. The parameter $\tau_{w}$ is set as a function of yield strength LE, the dimensionless $\mathrm{He}$ and $\mathrm{Re}$, and the actual friction factor, making the implicit Equation 11.

$$
f=\frac{2 H e_{H B}}{R e_{H B}^{2}}+\frac{16}{R e_{H B}}[A]^{-n_{H B}}
$$

Where:

$$
[A]=\left[\begin{array}{l}
\left(1-\frac{L E_{H B}}{\tau_{w}}\right)^{3}+\frac{2\left(3 n_{H B}+1\right)}{\left(2 n_{H B}+1\right)}\left(\frac{L E_{H B}}{\tau_{w}}\right)\left(1-\frac{L E_{H B}}{\tau_{w}}\right)^{2}+ \\
\frac{\left(3 n_{H B}+1\right)}{\left(n_{H B}+1\right)}\left(\frac{L E_{H B}}{\tau_{w}}\right)^{2}\left(1-\frac{L E_{H B}}{\tau_{w}}\right)
\end{array}\right]
$$

$$
\begin{aligned}
R e_{H B} & =\frac{8 D^{n_{H B}}\langle v\rangle^{2-n_{H B}} \rho}{k_{H B}\left[2\left(3 n_{H B}+1\right) / n_{H B}\right]^{n_{H B}}} \\
H e_{H B} & =\operatorname{Re}_{H B}^{2} \frac{L E_{H B}}{\rho\langle v\rangle^{2}} \\
\frac{L E_{H B}}{\tau_{w}} & =2 \frac{H e_{H B}}{f R e_{H B}^{2}}
\end{aligned}
$$

Where $\mathrm{He}_{\text {Hв }}$ and $\mathrm{Re}_{\text {Hв }}$ are the Hedstrom number and the generalized Reynolds number for the Herschel-Buckley model, $[A]$ is the parameter for Equation 11 , and $\tau_{w}$ is the wall shear stress. For non-Newtonian fluids in turbulent flow, among several friction factor correlations, Tomita (1959) developed Equation 16. This equation is used in the study of Bingham fluids in circular ducts of different diameters.

$f=\lambda / 4$

$\frac{1}{\sqrt{\lambda}}=2 \log \left(\operatorname{Re} \frac{\sqrt{\lambda}}{2}\right)-0.2$

Churchill (1977) proposed Equation 18 by combining equations available in literature. This one calculates the friction factor in the three flow regimes, for smooth and rough pipes with dependence on Reynolds number and relative roughness $(\varepsilon / D)$.

$f=2\left[\left(\frac{8}{\operatorname{Re}}\right)^{12}+\frac{1}{(A+B)^{3 / 2}}\right]^{\frac{1}{12}}$ 
Where:

$$
\begin{aligned}
& A=\left[2,457 \ln \frac{1}{\left(\frac{7}{\operatorname{Re}}\right)^{0.9}+0.27 \frac{\varepsilon}{\mathrm{D}}}\right]^{16} \\
& B=\left(\frac{37530}{\operatorname{Re}}\right)^{16}
\end{aligned}
$$

Ellis \& George (1977) proposed Equation 21 to calculate the friction factor in turbulent flow with dependence only on the Reynolds number.

$$
f=0.00454+0.645 \operatorname{Re}^{-0.70}
$$

Darby \& Melson (1981) developed an expression, Equation 22, to estimate the friction factor of fluids that follow the Bingham model. This equation is applicable to the three flow regimes.

$f=\left(f_{L}^{m}+f_{T}^{m}\right)^{1 / m}$

Where:

$$
\begin{aligned}
& f_{L}=\frac{16}{\operatorname{Re}}\left[1+\frac{H e}{6 R e}-\frac{H e^{4}}{3 f_{L}^{3} R e^{7}}\right] \\
& f_{T}=\frac{10^{a}}{\operatorname{Re} e^{0.193}} \\
& m=1.7+\frac{40000}{\operatorname{Re}}
\end{aligned}
$$

$$
a=-1.378\left[1+0.146 \exp \left(-2.9 \times 10^{-5} \mathrm{He}\right)\right]
$$

Where $f_{L}$ is the laminar friction factor, $f_{T}$ is the turbulent friction factor, $m$ is the parameter of Equation 22, $\mathrm{He}$ is the Hedstrom number, and $a$ is the parameter of Equation 24. From the friction factor values, Gomes (1987) proposed an explicit way or, in some cases a simplified one, to calculate the friction factor. Gomes (1987) did this by using Dodge and Metzner, Ostwald de Waele, and Frank Schuh equations, proposed by the least square method. See Equations 27-29.

$f=0.060 n^{0.462} \operatorname{Re}^{-0.223}$

$$
\begin{aligned}
& f=0.069 n^{0.666} R e^{-0.235} \\
& f=0.110 n^{0.616} R e^{-0.287}
\end{aligned}
$$

Darby et al. (1992) suggested alterations to Equation 26, originally from Darby \& Melson (1981), to improve the friction factor estimated in turbulent flow. The result is Equation 30.

$$
a=-1.47\left[1+0.146 \exp \left(-2.9 \times 10^{-5} \mathrm{He}\right)\right]
$$

\subsection{Hydraulic diameter correlations for annular ducts}

The hydraulic diameter correlations generate geometric factors capable of representing the annular duct as a circular one. This method allows the use of already well-established fluid mechanics equations.

Bourgoyne et al. (1991) presented the two equations below. Equation 31 is known as "slot". This equation is valid when the ratio of inner and outer diameters is greater than 0.3.

$$
D H_{1}=0.816\left(D_{2}-D_{1}\right)
$$

The second correlation evaluated was developed analytically using the hydraulic radius theory, Equation 32.

$$
D H_{2}=4 R_{H}=\left(D_{2}-D_{1}\right)
$$

In Equations 31 and 32, $\mathrm{DH}_{1}$ and $\mathrm{DH}_{2}$ are hydraulic diameter correlations and $D_{2}$ and $D_{1}$ are, respectively, the inner diameter of the outer tube and the outer diameter of the inner tube.

\section{EXPERIMENTAL DESCRIPTION}

\subsection{Description of the unit}

The unit shown in Figure 1 consists of a system operating in closed circuit, composed of galvanized iron tubes, a helical pump of $25 \mathrm{HP}$, responsible for the fluid flow from the mixing tank to the entire system, for flow rates of up to $20 \mathrm{~m}^{3} / \mathrm{h}$, and pressures of an order of $12 \mathrm{kgf} / \mathrm{cm}^{2}$. The experimental sections were composed of a circular tube 1" in diameter and three concentric annular with the following outer to inner diameter ratios: 


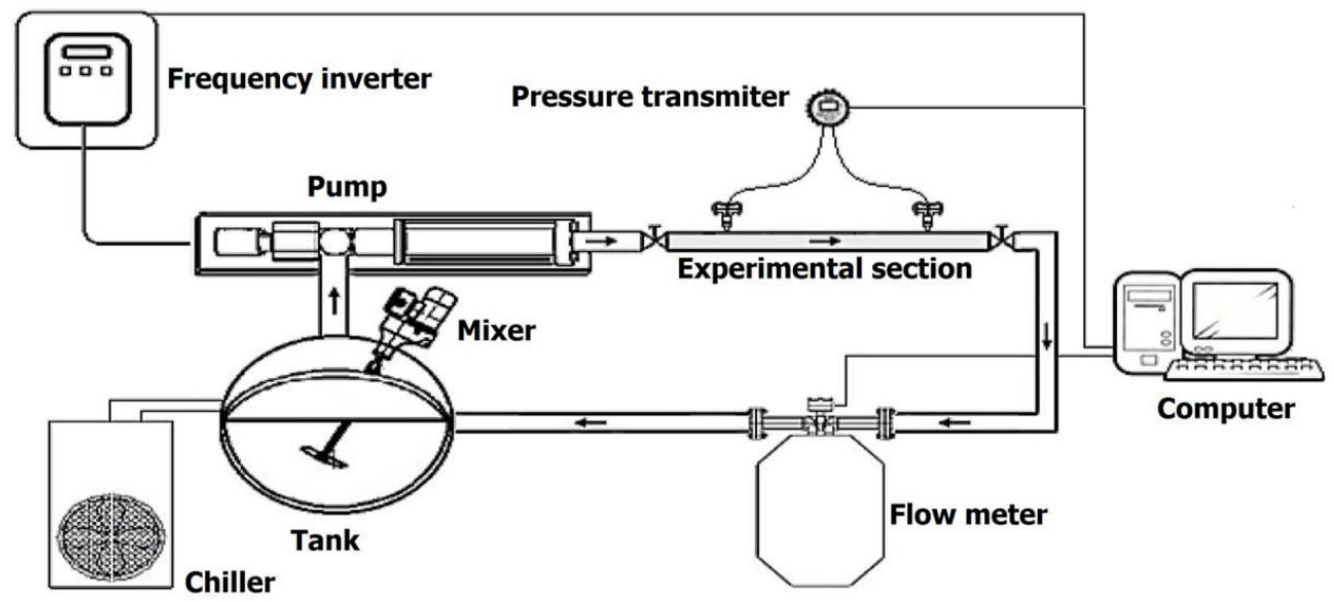

Figure 1. Experimental unit for cement slurries flow.

Annular 1 (1 1/4" - 1/2"), Annular 2 (1 1/2" - 1"); and Annular $3\left(1 \frac{1}{4 \prime}-3 / 4^{\prime \prime}\right)$.

To obtain the pressure drop in each experimental section, a differential pressure gauge with remote seals was calibrated from 0 to $7 \mathrm{kgf} / \mathrm{cm}^{2}$. A Coriolis mass flow meter provided the flow temperature and density of the slurries. The mixing tank was equipped with a mixer and heating system. It could also be cooled using a chiller with a cooling power of $15000 \mathrm{kCal} / \mathrm{h}$.

The uncertainties of the experimental variables are presented in Table 1 . These uncertainties were supplied by the equipment manufacturers. In the case of Fann viscometer 35A, the half of the smallest scale division was used to estimate the error in the measurement. Uncertainties related to the length of the straight section, the diameter pipelines, and the acceleration of gravity were considered insignificant.

\subsection{Analyzed fluid}

The analyzed cement slurry was formulated by Petrobras Research Center (CENPES), and produced in a mixing tank unit under controlled temperature. The slurry was composed of a mixture consisting of G-class cement from Holcim Company, fresh water, and additives from Schlumberger Company (midtemp retarder and antifoam agent).

\subsection{Experimental procedure}

The fluids analyzed were pumped through the test section at different flow rates. During the flow testing, the pressure drop was measured using differential pressure transducers. The fluids were analyzed at temperatures of 15,25 , and $60^{\circ} \mathrm{C}$. Parallel to the pressure drop experiments, the rheological data were obtained in a FANN-35A viscometer at the predetermined flow rate.

Table 1. Uncertainty of experimental variables.

\begin{tabular}{ccccc}
\hline Experimental variable & & $2 \sigma_{i}$ & & Unit \\
\cline { 1 - 1 } W (mass flow rate) & & 0.075 & & $\%$ span \\
\hline$\rho$ (density) & 0.18 & & $\%$ span \\
\hline$\theta$ (angular deformation) & 0.15 & & $\%$ span \\
\hline
\end{tabular}




\section{RESULTS AND DISCUSSION}

\subsection{Evaluation of rheological behavior}

The rheological data were obtained by using a viscometer FANN 35A under controlled temperature. To evaluate the rheology of the fluid over time, tests were conducted over each experiment at a predetermined flow rate. Table 2 presents the averages of rheological parameters as well as the correlation coefficient $\left(R^{2}\right)$ and the uncertainty obtained for each model. For the calculation of this uncertainty, the coverage factor, which equals 2 , was associated with the standard deviation.

One can see, from Table 2, that the HerschelBuckley model presented the best correlation coefficient. The Bingham model had a good correlation coefficient at 15 and $25^{\circ} \mathrm{C}$. The power law model did not present satisfactory results in the analyzed temperatures.

\subsection{Evaluation of hydraulic diameter correlations}

To evaluate the hydraulics correlations in all cases, it was used the graphs of pressure drop versus flow rate. In these graphs, the average percentage error of each hydraulic diameter correlation is presented. This error evaluates the gap between the theoretical and experimental pressure loss. To exemplify the way of evaluation, results obtained using Annular 3 at $25^{\circ} \mathrm{C}$ are shown in Figure 2. In this example it was considered only laminar regime to evaluate the two hydraulic diameter correlations using the Bingham model.

Table 2. Average rheological parameters obtained.

\begin{tabular}{|c|c|c|c|c|c|c|c|c|c|c|c|c|c|}
\hline \multirow{2}{*}{\multicolumn{2}{|c|}{$\begin{array}{l}\text { Ducts } \\
\mathrm{T},{ }^{\circ} \mathrm{C} \\
\end{array}$}} & \multicolumn{3}{|c|}{ Circular 1" } & \multicolumn{3}{|c|}{$\begin{array}{c}\text { Annular } 1 \\
(2 "-1 \text { 1/2") }\end{array}$} & \multicolumn{3}{|c|}{$\begin{array}{c}\text { Annular } 2 \\
\text { (1 1/2"-1") }\end{array}$} & \multicolumn{3}{|c|}{$\begin{array}{c}\text { Annular } 3 \\
\text { (1 1/4"-3/4") }\end{array}$} \\
\hline & & 15 & 25 & 60 & 15 & 25 & 60 & 15 & 25 & 60 & 15 & 25 & 60 \\
\hline \multirow{5}{*}{ 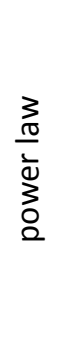 } & $\mathrm{n}$ & 0.34 & 0.28 & 0.18 & 0.39 & 0.26 & 0.13 & 0.39 & 0.31 & 0.14 & 0.41 & 0.32 & 0.22 \\
\hline & $2 \sigma(n)$ & 0.06 & 0.02 & 0.02 & 0.03 & 0.07 & 0.02 & 0.07 & 0.05 & 0.04 & 0.06 & 0.06 & 0.02 \\
\hline & K, Pa.s ${ }^{n}$ & 2.56 & 2.84 & 6.04 & 1.43 & 2.95 & 11.62 & 1.25 & 1.5 & 8.06 & 1.25 & 1.49 & 3.42 \\
\hline & $2 \sigma(K)$ & 0.97 & 0.41 & 1.28 & 0.14 & 2.05 & 2.45 & 0.33 & 0.56 & 3.58 & 0.22 & 0.79 & 0.68 \\
\hline & $\mathrm{R}^{2}$ & 0.925 & 0.878 & 0.915 & 0.930 & 0.881 & 0.951 & 0.918 & 0.891 & 0.914 & 0.927 & 0.898 & 0.945 \\
\hline \multirow{5}{*}{ 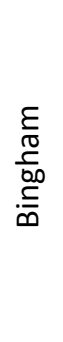 } & LE, Pa & 5.73 & 5.4 & 9.42 & 3.45 & 5.22 & 16.59 & 2.92 & 3.02 & 11.59 & 3.04 & 3.05 & 6.01 \\
\hline & $2 \sigma(\mathrm{LE})$ & 1.50 & 0.50 & 1.60 & 0.24 & 2.77 & 2.59 & 0.35 & 0.67 & 4.34 & 0.28 & 1.08 & 1.06 \\
\hline & VP, Pa.s & 0.042 & 0.029 & 0.022 & 0.035 & 0.024 & 0.024 & 0.03 & 0.02 & 0.019 & 0.035 & 0.021 & 0.018 \\
\hline & $2 \sigma(V P)$ & 0.004 & 0.001 & 0.002 & 0.006 & 0.002 & 0.002 & 0.008 & 0.001 & 0.002 & 0.009 & 0.001 & 0.002 \\
\hline & $\mathrm{R}^{2}$ & 0.992 & 0.995 & 0.977 & 0.997 & 0.997 & 0.913 & 0.998 & 0.996 & 0.930 & 0.999 & 0.997 & 0.960 \\
\hline \multirow{7}{*}{ 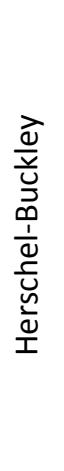 } & $\mathrm{n}$ & 0.81 & 0.87 & 0.68 & 0.9 & 0.89 & 0.43 & 0.92 & 0.92 & 0.55 & 0.93 & 0.91 & 0.60 \\
\hline & $2 \sigma(n)$ & 0.05 & 0.06 & 0.07 & 0.04 & 0.11 & 0.10 & 0.12 & 0.13 & 0.35 & 0.05 & 0.16 & 0.18 \\
\hline & K, Pa.s ${ }^{n}$ & 0.14 & 0.07 & 0.18 & 0.07 & 0.05 & 1.00 & 0.05 & 0.04 & 0.6 & 0.06 & 0.04 & 0.27 \\
\hline & $2 \sigma(K)$ & 0.04 & 0.03 & 0.08 & 0.03 & 0.03 & 0.57 & 0.04 & 0.02 & 1.00 & 0.02 & 0.04 & 0.24 \\
\hline & $\mathrm{LE}, \mathrm{Pa}$ & 4.71 & 4.44 & 8.25 & 3.02 & 4.9 & 13.1 & 2.64 & 2.82 & 9.54 & 2.76 & 2.81 & 4.62 \\
\hline & $2 \sigma(L E)$ & 1.54 & 0.59 & 1.32 & 0.16 & 2.55 & 1.50 & 0.63 & 0.96 & 1.93 & 0.22 & 1.24 & 0.53 \\
\hline & $\mathrm{R}^{2}$ & 0.999 & 0.998 & 0.998 & 0.999 & 0.999 & 0.996 & 0.999 & 0.998 & 0.965 & 1.000 & 0.999 & 0.996 \\
\hline
\end{tabular}




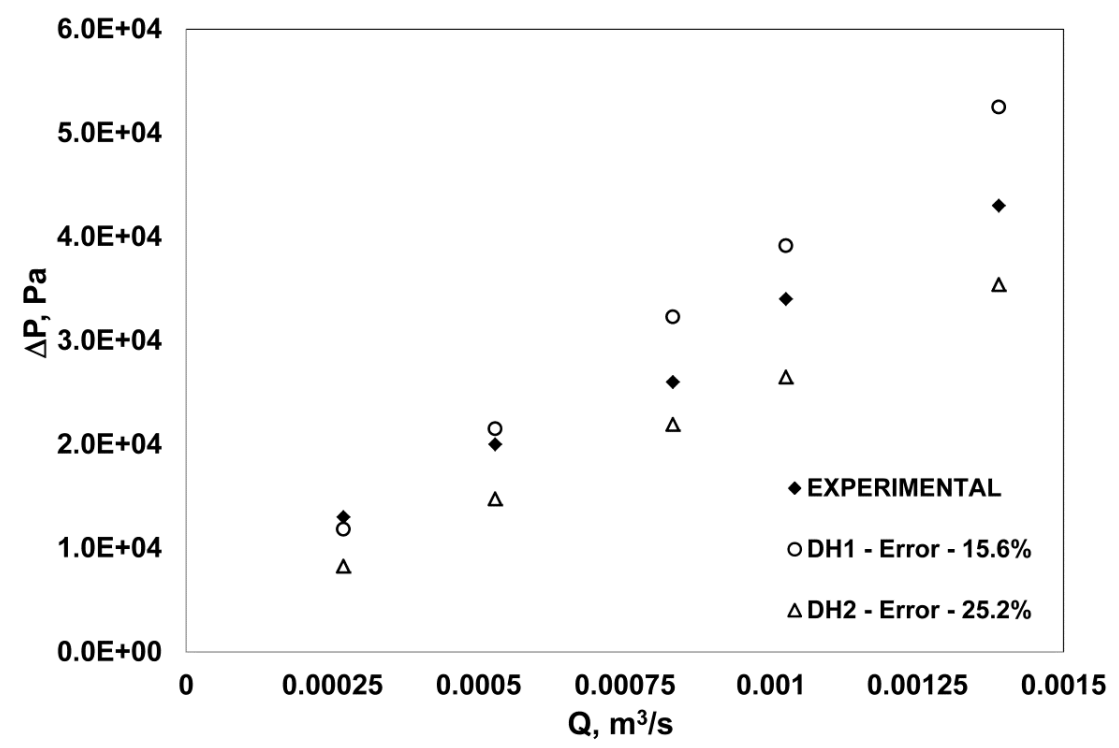

Figure 2. Pressure drop vs. flow rate in cement slurry flow at $25^{\circ} \mathrm{C}$, in Annular duct $3(11 / 4$ " and $3 / 4 ")$, Bingham model.

Analyzing Figure 2, one can notice that the $\mathrm{DH}_{1}$ correlation (slot) was the one closest to the experimental results, using the Bingham model. The same graphic analysis was performed in the other annular, also using the power law and Herschel-Buckley models. The average absolute percentage errors of the hydraulic diameter correlations are shown in Table 3 . In this table, the absolute percentage errors of less than $25 \%$ are highlighted.

According to the average error presented in Table 3, one can observe that the correlation $\mathrm{DH}_{2}$ is more appropriate, for the geometry of the annular studied, using Bingham and Herschel-Buckley models.

Table 3. Average absolute percentage error of hydraulic diameter correlations.

\begin{tabular}{|c|c|c|c|c|c|c|c|c|c|c|}
\hline \multirow{2}{*}{$\begin{array}{l}\text { Rheological } \\
\text { model }\end{array}$} & \multirow[t]{2}{*}{$\mathrm{T},{ }^{\circ} \mathrm{C}$} & \multirow{2}{*}{$\begin{array}{l}\text { Average correlation } \\
\text { coefficient }\left(R^{2}\right)\end{array}$} & \multicolumn{2}{|c|}{$\begin{array}{c}\text { Annular } 1 \\
(2 "-11 / 2 ") \\
\end{array}$} & \multicolumn{2}{|c|}{$\begin{array}{c}\text { Annular } 2 \\
\left(11 / 2^{\prime \prime}-1 "\right) \\
\end{array}$} & \multicolumn{2}{|c|}{$\begin{array}{c}\text { Annular } 3 \\
(11 / 4 "-3 / 4 ") \\
\end{array}$} & \multicolumn{2}{|c|}{$\begin{array}{c}\text { Average } \\
\text { error }\end{array}$} \\
\hline & & & $\mathrm{DH}_{1}$ & $\mathrm{DH}_{2}$ & $\mathrm{DH}_{1}$ & $\mathrm{DH}_{2}$ & $\mathrm{DH}_{1}$ & $\mathrm{DH}_{2}$ & $\mathrm{DH}_{1}$ & $\mathrm{DH}_{2}$ \\
\hline \multirow{3}{*}{ 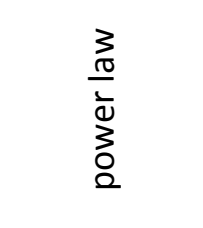 } & 15 & 0.9251 & 25.7 & 44.3 & 30.3 & 47.6 & 31.1 & 48.5 & 29.0 & 46.8 \\
\hline & 25 & 0.8898 & 42.1 & 55.3 & 41.3 & 55.1 & 38.4 & 53.1 & 40.6 & 54.5 \\
\hline & 60 & 0.9364 & 23.5 & 30.1 & 20.3 & 33.4 & 15.2 & 38.0 & 19.7 & 33.8 \\
\hline \multirow{3}{*}{ 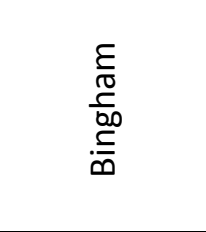 } & 15 & 0.9978 & 108.6 & 40.2 & 44.4 & 7.4 & 31.0 & 13.6 & 61.3 & 20.4 \\
\hline & 25 & 0.9964 & 69.2 & 20.6 & 26.4 & 18.5 & 15.6 & 25.2 & 37.1 & 21.4 \\
\hline & 60 & 0.9343 & 103.4 & 44.7 & 51.3 & 7.7 & 31.5 & 7.2 & 62.1 & 19.9 \\
\hline \multirow{3}{*}{ 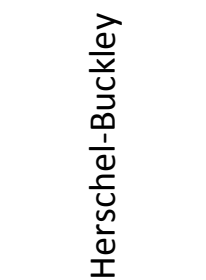 } & 15 & 0.9993 & 73.3 & 19.3 & 33.5 & 12.0 & 24.1 & 13.7 & 43.6 & 15.0 \\
\hline & 25 & 0.9987 & 59.1 & 15.5 & 11.9 & 27.1 & 11.8 & 25.1 & 27.6 & 22.6 \\
\hline & 60 & 0.9859 & 15.2 & 10.5 & 18.9 & 12.4 & 12.4 & 22.7 & 15.5 & 15.2 \\
\hline
\end{tabular}




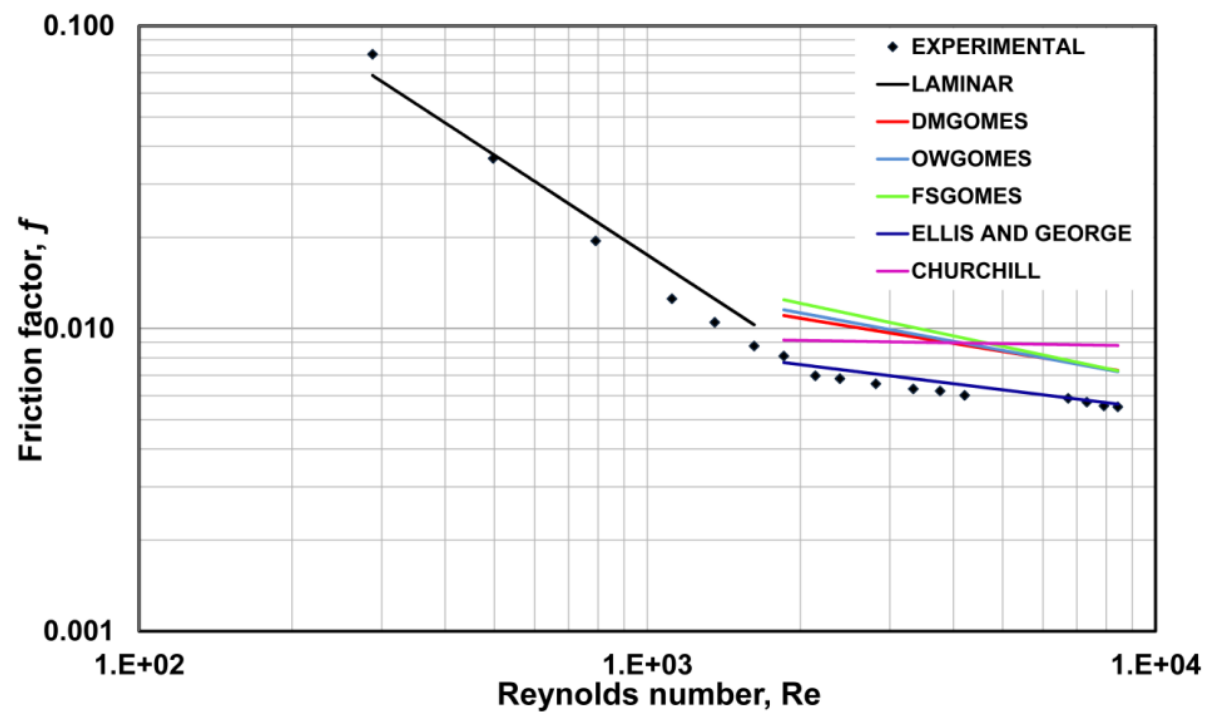

Figure 3. Friction factor vs. Reynods number of Cement Slurry flow in Annular 1 , at $25^{\circ} \mathrm{C}$, Herschel-Buckley model, and $\mathrm{DH}_{2}$ correlation to calculate the hydraulic diameter.

\subsection{Evaluation of friction factor correlation}

Equation 5 was used to determine the experimental friction factor. These experimental results were compared with the ones obtained by the correlations presented in the literature review for laminar and turbulent flows. Figure 3 illustrates the evaluation of friction factor correlations obtained in Annular 1 at $25^{\circ} \mathrm{C}$ using the HerschelBuckley rheological model and correlation $\mathrm{DH}_{2}$ for hydraulic diameter.

Looking at Figure 3, one can see that, when the cement slurry flows in Annular 1 , using the Herschel-Buckley model, a satisfactory estimate is obtained for the friction factor in turbulent flow,

Table 4. Average absolute percentage error of friction factor correlations at $15^{\circ} \mathrm{C}$.

\begin{tabular}{|c|c|c|c|c|c|c|c|c|c|c|}
\hline \multirow{2}{*}{\multicolumn{2}{|c|}{$\begin{array}{l}\text { Friction factor correlations } \\
\qquad\left(15^{\circ} \mathrm{C}\right)\end{array}$}} & \multirow{2}{*}{$\begin{array}{l}\text { Circular } \\
1^{\prime \prime}\end{array}$} & \multicolumn{2}{|c|}{$\begin{array}{c}\text { Annular } 1 \\
\left(2^{\prime \prime}-11 / 2^{\prime \prime}\right) \\
\end{array}$} & \multicolumn{2}{|c|}{$\begin{array}{c}\text { Annular } 2 \\
\left(11 / 2^{\prime \prime}-1^{\prime \prime}\right) \\
\end{array}$} & \multicolumn{2}{|c|}{$\begin{array}{r}\text { Annular } 3 \\
\left(11 / 4^{"-}-3 / 4^{\prime \prime}\right) \\
\end{array}$} & \multicolumn{2}{|c|}{$\begin{array}{c}\text { Annular } \\
\text { (average error) }\end{array}$} \\
\hline & & & $\mathrm{DH}_{1}$ & $\mathrm{DH}_{2}$ & $\mathrm{DH}_{1}$ & $\mathrm{DH}_{2}$ & $\mathrm{DH}_{1}$ & $\mathrm{DH}_{2}$ & $\mathrm{DH}_{1}$ & $\mathrm{DH}_{2}$ \\
\hline \multirow{6}{*}{$\begin{array}{l}\frac{3}{0} \\
\frac{1}{0} \\
\vdots \\
0 \\
0\end{array}$} & Laminar & 15.6 & 25.7 & 44.3 & 30.3 & 47.6 & 31.1 & 48.5 & 29.0 & 46.8 \\
\hline & DM Gomes & 32.6 & 14.8 & 31.7 & 31.5 & 45.1 & 32.2 & 45.7 & 26.2 & 40.8 \\
\hline & OW Gomes & 45.2 & 28.3 & 42.5 & 42.3 & 53.8 & 42.4 & 53.9 & 37.7 & 50.1 \\
\hline & FS Gomes & 43.8 & 26.4 & 41.3 & 41.0 & 53.0 & 41.5 & 53.4 & 36.3 & 49.2 \\
\hline & Ellis and George & 12.6 & 12.1 & 18.8 & 17.1 & 32.9 & 19.5 & 34.9 & 16.2 & 28.9 \\
\hline & Churchill & 13.2 & 34.3 & 7.9 & 10.4 & 13.6 & 6.7 & 16.9 & 17.1 & 12.8 \\
\hline \multirow{6}{*}{ 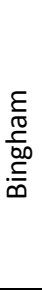 } & Laminar & 14.5 & 108.6 & 40.2 & 44.4 & 7.4 & 31 & 13.6 & 61.3 & 20.4 \\
\hline & Darby and Melson & 19.4 & 16.8 & 11.5 & 12.5 & 32.2 & 15.2 & 31.9 & 14.8 & 25.2 \\
\hline & Tomita & 17.7 & 99.7 & 53.2 & 47.5 & 12.8 & 41.5 & 12.3 & 62.9 & 26.1 \\
\hline & Darby et al. & 36.5 & 11.6 & 30.6 & 31.3 & 46.8 & 33.5 & 46.5 & 25.5 & 41.3 \\
\hline & Ellis and George & 6.5 & 44.2 & 13.1 & 9 & 16.3 & 11.3 & 16.8 & 21.5 & 15.4 \\
\hline & Churchill & 33.6 & 95.9 & 56.5 & 55.7 & 24.2 & 48.4 & 29.9 & 66.7 & 36.9 \\
\hline \multirow{6}{*}{ 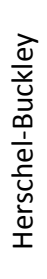 } & Laminar & 14.1 & 73.3 & 19.3 & 33.5 & 12.0 & 24.1 & 13.7 & 43.6 & 15.0 \\
\hline & DM Gomes & 15.0 & 86.5 & 46.0 & 41.8 & 11.2 & 37.9 & 13.4 & 55.4 & 23.5 \\
\hline & OW Gomes & 13.5 & 92.1 & 50.0 & 44.7 & 12.6 & 40.9 & 14 & 59.2 & 25.5 \\
\hline & FS Gomes & 13.8 & 105.1 & 58.7 & 50.9 & 15.9 & 46.3 & 14.3 & 67.4 & 29.6 \\
\hline & Ellis and George & 7.8 & 35.5 & 11.2 & 5.3 & 19.7 & 9.2 & 22.7 & 16.7 & 17.9 \\
\hline & Churchill & 29.1 & 92.2 & 48.1 & 47.2 & 21.4 & 43.3 & 23.9 & 60.9 & 31.1 \\
\hline
\end{tabular}


using $\mathrm{DH}_{2}$ (hydraulic radius) combined with the Ellis \& George (1977) correlation.

Summarizing the results, Tables 4-6 present the average absolute percentage errors of friction factor correlations. Each table shows results at 15,
25 , and $60^{\circ} \mathrm{C}$. For the annular ducts, the friction factor correlations are evaluated using the two correlations presented $\left(\mathrm{DH}_{1}\right.$ and $\left.\mathrm{DH}_{2}\right)$. In these tables, the average absolute percentage errors of less than $25 \%$ are highlighted.

Table 5. Average absolute percentage error of friction factor correlations at $25^{\circ} \mathrm{C}$.

\begin{tabular}{|c|c|c|c|c|c|c|c|c|c|c|}
\hline \multirow{2}{*}{\multicolumn{2}{|c|}{$\begin{array}{l}\text { Friction factor correlations } \\
\qquad\left(25^{\circ} \mathrm{C}\right)\end{array}$}} & \multirow{2}{*}{$\begin{array}{c}\text { Circular } \\
1 "\end{array}$} & \multicolumn{2}{|c|}{$\begin{array}{c}\text { Annular } 1 \\
\left(2^{\prime \prime}-11 / 2 "\right)\end{array}$} & \multicolumn{2}{|c|}{$\begin{array}{c}\text { Annular } 2 \\
\left(11 / 2^{\prime \prime}-1 "\right)\end{array}$} & \multicolumn{2}{|c|}{$\begin{array}{c}\text { Annular } 3 \\
\left(11 / 4^{\prime \prime}-3 / 4 "\right)\end{array}$} & \multicolumn{2}{|c|}{$\begin{array}{c}\text { Annular } \\
\text { (average error) }\end{array}$} \\
\hline & & & $\mathrm{DH}_{1}$ & $\mathrm{DH}_{2}$ & $\mathrm{DH}_{1}$ & $\mathrm{DH}_{2}$ & $\mathrm{DH}_{1}$ & $\mathrm{DH}_{2}$ & $\mathrm{DH}_{1}$ & $\mathrm{DH}_{2}$ \\
\hline \multirow{6}{*}{ 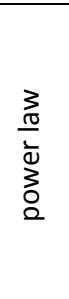 } & Laminar & 18.5 & 42.1 & 55.3 & 41.3 & 55.1 & 38.4 & 53.1 & 40.6 & 54.5 \\
\hline & DM Gomes & 37.2 & 33.3 & 46.2 & 37.6 & 49.8 & 33.9 & 46.8 & 34.9 & 47.6 \\
\hline & OW Gomes & 50.6 & 48.8 & 58.7 & 49.9 & 59.7 & 46.8 & 57.2 & 48.5 & 58.5 \\
\hline & FS Gomes & 49.6 & 47.2 & 57.5 & 49.3 & 59.4 & 46.2 & 56.9 & 47.6 & 57.9 \\
\hline & Ellis and George & 10.0 & 5.5 & 18.4 & 12.7 & 29.2 & 9.0 & 24.8 & 9.1 & 24.1 \\
\hline & Churchill & 12.2 & 27.1 & 4.5 & 11.0 & 15.7 & 12.7 & 12.2 & 16.9 & 10.8 \\
\hline \multirow{6}{*}{ 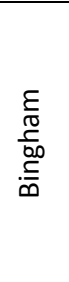 } & Laminar & 10.1 & 69.2 & 20.6 & 26.4 & 18.5 & 15.6 & 25.2 & 37.1 & 21.4 \\
\hline & Darby and Melson & 15.3 & 14.2 & 9.7 & 9.6 & 28.8 & 5.4 & 25.0 & 9.7 & 21.2 \\
\hline & Tomita & 17.6 & 95.4 & 51.7 & 47.8 & 14.0 & 53.0 & 18.1 & 65.4 & 27.9 \\
\hline & Darby et al. & 33.1 & 11.3 & 29.1 & 29.0 & 44.1 & 25.0 & 41.1 & 21.8 & 38.1 \\
\hline & Ellis and George & 6.8 & 41.7 & 11.0 & 10.3 & 13.6 & 16.1 & 9.3 & 22.7 & 11.3 \\
\hline & Churchill & 32.9 & 91.0 & 51.8 & 55.3 & 27.3 & 69.4 & 32.6 & 71.9 & 37.2 \\
\hline \multirow{6}{*}{ 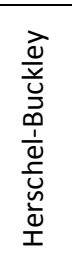 } & Laminar & 11.3 & 59.1 & 15.5 & 11.9 & 27.1 & 11.8 & 25.1 & 27.6 & 22.6 \\
\hline & DM Gomes & 19.3 & 79.6 & 41.8 & 54.0 & 19.4 & 53.1 & 19.1 & 62.2 & 26.8 \\
\hline & OW Gomes & 18.9 & 83.4 & 44.1 & 58.9 & 22.8 & 55.6 & 20.7 & 66.0 & 29.2 \\
\hline & FS Gomes & 17.4 & 93.8 & 50.4 & 64.0 & 25.7 & 58.3 & 22.1 & 72.0 & 32.7 \\
\hline & Ellis and George & 7.0 & 32.2 & 4.8 & 8.5 & 15.2 & 12.0 & 12.1 & 17.6 & 10.7 \\
\hline & Churchill & 28.5 & 80.4 & 44.2 & 63.7 & 26.8 & 66.5 & 28.5 & 70.2 & 33.2 \\
\hline
\end{tabular}

Table 6. Average absolute percentage error of friction factor correlations at $60^{\circ} \mathrm{C}$.

\begin{tabular}{|c|c|c|c|c|c|c|c|c|c|c|}
\hline \multirow{2}{*}{\multicolumn{2}{|c|}{$\begin{array}{l}\text { Friction factor correlations } \\
\qquad\left(60^{\circ} \mathrm{C}\right)\end{array}$}} & \multirow{2}{*}{$\begin{array}{l}\text { Circular } \\
1 "\end{array}$} & \multicolumn{2}{|c|}{$\begin{array}{c}\text { Annular } 1 \\
\left(2^{\prime \prime}-11 / 2^{\prime \prime}\right)\end{array}$} & \multicolumn{2}{|c|}{$\begin{array}{l}\text { Annular } 2 \\
\left(11 / 2^{\prime \prime}-1 "\right)\end{array}$} & \multicolumn{2}{|c|}{$\begin{array}{c}\text { Annular } 3 \\
\left(11 / 4^{\prime \prime}-3 / 4^{\prime \prime}\right)\end{array}$} & \multicolumn{2}{|c|}{$\begin{array}{c}\text { Annular } \\
\text { (average error) }\end{array}$} \\
\hline & & & $\mathrm{DH}_{1}$ & $\mathrm{DH}_{2}$ & $\mathrm{DH}_{1}$ & $\mathrm{DH}_{2}$ & $\mathrm{DH}_{1}$ & $\mathrm{DH}_{2}$ & $\mathrm{DH}_{1}$ & $\mathrm{DH}_{2}$ \\
\hline \multirow{6}{*}{$\begin{array}{l}3 \\
\frac{3}{0} \\
\bar{d} \\
\vdots \\
0 \\
\varrho\end{array}$} & Laminar & 13.7 & 23.5 & 30.1 & 20.3 & 33.4 & 15.2 & 38.0 & 19.7 & 33.8 \\
\hline & DM Gomes & 39.7 & 36.8 & 50.4 & 49.2 & 58.8 & 32.7 & 45.1 & 39.6 & 51.4 \\
\hline & OW Gomes & 57.2 & 57.1 & 66.2 & 66.2 & 72.5 & 49.7 & 59.0 & 57.7 & 65.9 \\
\hline & FS Gomes & 55.2 & 54.4 & 63.7 & 64.2 & 70.7 & 48.7 & 58.5 & 55.8 & 64.3 \\
\hline & Ellis and George & 9.9 & 25.8 & 10.9 & 11.9 & 14.4 & 14.9 & 12.2 & 17.5 & 12.5 \\
\hline & Churchill & 36.5 & 59.1 & 25.8 & 32.6 & 7.5 & 34.4 & 8.5 & 42.0 & 13.9 \\
\hline \multirow{6}{*}{ 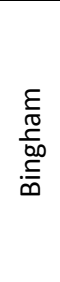 } & Laminar & 7.4 & 103.4 & 44.7 & 51.3 & 7.7 & 31.5 & 7.2 & 62.1 & 19.9 \\
\hline & Darby and Melson & 13.9 & 36.0 & 11.4 & 12.7 & 11.9 & 14.5 & 11.3 & 21.1 & 11.5 \\
\hline & Tomita & 33.3 & 130.1 & 80.5 & 71.8 & 32.7 & 78.4 & 37.6 & 93.4 & 50.3 \\
\hline & Darby et al. & 9.3 & 12.0 & 13.7 & 12.9 & 29.9 & 11.3 & 28.9 & 12.1 & 24.2 \\
\hline & Ellis and George & 13.6 & 67.6 & 32.8 & 30.6 & 9.5 & 37.7 & 11.0 & 45.3 & 17.8 \\
\hline & Churchill & 49.8 & 133.6 & 86.6 & 82.1 & 47.0 & 100.6 & 56.6 & 105.4 & 63.4 \\
\hline \multirow{6}{*}{ 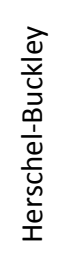 } & Laminar & 6.8 & 15.2 & 10.5 & 18.9 & 12.4 & 12.4 & 22.7 & 15.5 & 15.2 \\
\hline & DM Gomes & 15.2 & 22.0 & 7.8 & 9.9 & 26.1 & 31.3 & 8.5 & 21.1 & 14.1 \\
\hline & OW Gomes & 8.0 & 12.0 & 15.9 & 20.9 & 36.7 & 22.9 & 11.7 & 18.6 & 21.4 \\
\hline & FS Gomes & 7.9 & 15.4 & 14.0 & 21.4 & 36.7 & 22.3 & 11.8 & 19.7 & 20.8 \\
\hline & Ellis and George & 10.8 & 31.6 & 9.5 & 11.9 & 12.9 & 23.3 & 10.2 & 22.3 & 10.9 \\
\hline & Churchill & 39.1 & 77.8 & 39.8 & 38.2 & 10.3 & 62.4 & 28.3 & 59.5 & 26.1 \\
\hline
\end{tabular}


In Tables 4-6, the efficiency of Ellis \& George (1977) correlation was applied with quality for the three rheological models and temperatures studied. Other highlights include the Churchill (1977) correlation that, at temperatures of 15 and $25^{\circ} \mathrm{C}$, yielded good results for the power law model. The Darby \& Melson (1981) correlation, using the Bingham model at the three temperatures is also a highlight. The correlations proposed by Gomes (1987) with the HerschelBuckley model were effective for the turbulent regime at $60^{\circ} \mathrm{C}$.

For the laminar regime, using $\mathrm{DH}_{2}$ correlation, Herschel-Buckley and Bingham models achieved the best results as one can see in Tables 4-6. Using $\mathrm{DH}_{1}$ correlation, the power law model showed better results than using the $\mathrm{DH}_{2}$.

\section{CONCLUSIONS}

The Herschel-Buckley model was, in all cases, the one that best fitted the rheological data. The Bingham model was the second best option at 15 and $25^{\circ} \mathrm{C}$. The power law model presented unsatisfactory coefficients at the three different temperatures analyzed.

In the analysis of hydraulic diameter correlations, $\mathrm{DH}_{2}$ showed the lowest average percentage error. This result can be justified by the wide application of this equation, which allows its use in different geometries, regardless of the diameter ratio. In evaluating the friction factor correlations, in the laminar regime, there was a good prediction in circular duct and in the three annular ones using all the rheological models analyzed at the three temperatures. However, in annular ducts, Herschel-Buckley and Bingham models presented the best results using $\mathrm{DH}_{2}$. Power law model, on the other hand, presented better results using correlation $\mathrm{DH}_{1}$.

For the turbulent regime, the Ellis and George correlation (1977), associated with the $\mathrm{DH}_{2}$, showed good results in both annular and circular ducts. The correlation proposed by Churchill (1977) presented good results for the power law model at 15 and $25^{\circ} \mathrm{C}$. The correlation proposed by Darby and Melson (1981) presented good results when using the Bingham model, at the three temperatures evaluated. The correlations proposed by Gomes (1987), with the Herschel-Buckley model, were effective for the turbulent regime at $60^{\circ} \mathrm{C}$.

Based on the results, one can conclude that the performance at turbulent flow depends on the rheological model as well as on hydraulic diameter and friction factor correlations. In this context, the Ellis \& George (1977) correlation applied together with the hydraulic radius equation $\left(\mathrm{DH}_{2}\right)$ and with the Herschel-Buckley rheological model was the set of equations which had the lowest percentage errors in most of the cases analyzed.

\section{NOMENCLATURE}

a Parameter of equation 24 (dimensionless)

[A] Parameter of equation 11 (dimensionless)

A Parameter of equation 18 (dimensionless)

B Parameter of equation 18 (dimensionless)

D Diameter $(\mathrm{m})$

$D_{1}$ Outer diameter of the inner tube $(m)$

$D_{2}$ Inner diameter of the outer tube $(m)$

$\mathrm{DH}_{1}$ Hydraulic diameter (slot) (m)

$\mathrm{DH}_{2}$ Hydraulic diameter (hydraulic radius) (m)

$f$ Fanning friction factor (dimensionless)

$f_{L} \quad$ Laminar friction factor (dimensionless)

$\mathrm{f}_{\mathrm{T}}$ Turbulent friction factor (dimensionless)

He Hedstrom number (dimensionless)

$\mathrm{He}_{\mathrm{B}}$ Hedstrom number - Bingham model (dimensionless)

$\mathrm{He}_{\text {нв }}$ Hedstrom number - Herschel-Buckley model (dimensionless)

k Consistency index - power law model (Pa. $\left.s^{n}\right)$

$\mathrm{k}_{\mathrm{HB}}$ Consistency index - Herschel-Buckley model (Pa. $s^{n}$ )

$L$ Length of the straight section (m)

$\mathrm{LE}_{\mathrm{B}} \quad$ Yield stress for Bingham fluid (Pa)

$\mathrm{LE}_{\mathrm{HB}}$ Yield stress for Herschel-Buckley fluid (Pa)

m Parameter of equation 22 (dimensionless)

$\mathrm{n}$ Behavior index - power law model (dimensionless) 
$\mathrm{n}_{\text {нв }}$ Behavior index - Herschel-Buckley model (dimensionless)

Q Flow rate $\left(\mathrm{m}^{3} / \mathrm{s}\right)$

$\mathrm{R}_{\mathrm{H}}$ Hydraulic radius $(\mathrm{m})$

$\mathrm{R}^{2}$ Correlation coefficient (dimensionless)

Re Reynolds number (dimensionless)

$\operatorname{Re}_{\mathrm{B}}$ Generalized Reynolds number - Bingham model (dimensionless)

$\mathrm{Re}_{\mathrm{HB}}$ Generalized Reynolds number - HerschelBuckley model (dimensionless)

$\operatorname{Re}_{\mathrm{p}}$ Generalized Reynolds number - power law model (dimensionless)

$v$ or $<\mathrm{v}>$ Average velocity $(\mathrm{m} / \mathrm{s})$

$\mathrm{VP}_{\mathrm{B}}$ Bingham plastic viscosity (Pa.s)

W Mass flow rate $(\mathrm{kg} / \mathrm{min})$

\section{Greek Letters}

$\Delta \mathrm{P}$ Pressure loss $(\mathrm{Pa})$

$\Delta \mathrm{P}_{\text {calc }}$ Pressure loss calculated by correlation ( $\left.\mathrm{Pa}\right)$

$\Delta \mathrm{P}_{\text {exper }}$ Experimental pressure loss $(\mathrm{Pa})$

$\rho$ Fluid density $\left(\mathrm{kg} \cdot \mathrm{m}^{-3}\right)$

$\varepsilon$ Pipe's roughness $(\mathrm{m})$

$\gamma$ Shear rate $\left(\mathrm{s}^{-1}\right)$

$\lambda$ Parameter of equation 16 (dimensionless)

$\mu$ Dynamic viscosity $\left(\mathrm{kg} \cdot \mathrm{m}^{-1} \cdot \mathrm{s}^{-1}\right)$

$\tau$ Shear stress $(\mathrm{Pa})$

$\tau_{\mathrm{w}}$ Wall shear stress $(\mathrm{Pa})$

$\theta$ Angular deformation (degree)

$\sigma$ Standard deviation

\section{ACKNOWLEDGMENTS}

The authors gratefully thank CENPES (PETROBRAS), FINEP, CNPq, CAPES, and PPGEQ/UFRRJ for the financial support.

\section{REFERENCES}

Bird, R. B.; Stewart, W. E.; Lightfoot, E. N.Transport Phenomena, John Wiley \& Sons, New York, 2002.

Bourgoyne Jr., A. T.; Millheim, K. K.; Chenevert, M. E.; Young Jr, F. S. Applied drilling engineering. Second printing, Society of Petroleum Engineers, Richardson, Texas; 1991.

Churchill, S. W. Friction factor equation spans all fluid flow regimes. J. Chem. Eng.; 1977.

Darby, R.; Melson, J. How to predict the friction factor for the flow of Bingham plastics. J. Chem. Eng., vol. 88, no. 26, p. 59-61; 1981.

Darby, R.; Mun, R.; Boger, D. V. Predict Friction Loss in Slurry Pipes, J. Chem. Eng., v.9, p.116.; 1992.

Ellis, R. C. and George, D. S. Practical interpretation on rheology, annular displacing torces. How to avoid by passing mud during primary cementing. World Oil; 1977.

Fox, R. W.; McDonald, A. T.; Pritchard, P. J. Introduction to Fluid Mechanics, John Wiley \& Sons, 6th ed., 2004.

Gomes, F. J. A. D. Hidráulica, fluidos de potência: racionalização do uso do fator de fricção, I Encontro Técnico sobre Informática na Perfuração, CAPER/87,Módulo 7, Salvador, Brasil, (in Portuguese);1987.

Lake, L. W.; Mitchel, R. F. Petroleum Engineering Handbook, Society of Petroleum Engineers, 2006.

Nelson, E. B. Well Cementing, Houston: Schlumberger Educational Services; 1990.

Tomita, Y. A. A study on non-Newtonian flow in pipe lines. Bulletin JSME, v.2, n.5, p. 10-16; 1959. http://dx.doi.org/10.1299/jsme1958.2.10 